\title{
WEIGHT CHANGE AND OEDEMA PATTERN IN DIFFERENT TYPES OF CHILDHOOD IDIOPATHIC NEPHRITIC SYNDROME
}

\author{
Roy RR', Islam $\mathrm{MR}^{2}$, Matin $\mathrm{A}^{3}$, Khan $\mathrm{R}^{4}$
}

\begin{abstract}
Introduction :

Nephrotic syndrome is characterized by massive proteinuria (urinary total protein $>1 \mathrm{gm} / \mathrm{m} 2$ /day) or urinary spot protein creatinine ratio of $>200 \mathrm{mg} / \mathrm{m} . \mathrm{mol}$, hypoalbuminemia, edema and hypercholesterolemia. The objectives of the study were to compare the differences in weight loss and weight gain after treatment and in edema pattern among different groups of childhood Idiopathic nephritic syndrome.

Methods:

Prospective observational study of 43 children with idiopathic nephritic syndrome (INS) selected randomly out of 480 children admitted with the disease at Bangabandhu Sheikh Mujib Medical University, Dhaka, Bangladesh from January 2003 to January 2005.

Results:

the weight loss were 4.36, 15.3 and 10.0 percent and weight gain afier steroid therapy were 1601, 0.26 and 3.49 percent weight among the children of steroid resistant, frequent relapse steroid- dependent and infrequent relapse first attack nephritic syndrome respectively.

Genital edema were present in 47.5, 54.5 and 30.8 percent, pleural effusions were seen in 42.I, 27.3 and 23.1 percent and pericardial effusions were seen in 10.5 and 9.1 percent of patients of steroid resistant, frequent relapse steroid- dependent and infrequent relapse first attack nephritic syndrome respectively.

Conclusion:

Weight loss and Genital edema were more in frequent relapse steroie- dependent nephritic syndrome but weight gain and pleural effusion were more in steroid resistant group.
\end{abstract}

Key words : Weight gain, edema, pleural effusion, pericardial \& nephritic syndrome

\section{Introduction}

Nephrotic syndrome is characterized by massive proteinuria (urinary total protein $>1 \mathrm{gm} / \mathrm{m} 2 /$ day or urinary spot protein creatinine ratio of $>200 \mathrm{mg} / \mathrm{m} \mathrm{mol}$ ), bypoalbuminemiaserum album in $<2.50 \mathrm{gm} / \mathrm{d} 1$ ), edema and hypercholesterolemia (serum cholesterol $>250 \mathrm{mg} / \mathrm{d1})^{1}$.

Clinical and biochemical features of pephritic syndrome (result from heavy proteinuria with consequent hypoalbuminemia and edema ${ }^{2}$.

1. Associate Professor Department of Pediatric Nephrology, Bangabandhu Seikh Mujib Medical University Dhaka.

2. Assistant Professor

3. Assistant Professor

4. Medical officer, NICR \& H Mohakhali Dhaka

Correspondence

D. Ranjit Ranjan Roy FCPS, MD

Associate Professoc, Department of Pediatrics Nephrology BSMMU.

Flat"F 5 NC Sheltech Sierra, 236 New Elephant Road. Dhaka 1205

Cell phoae : 01715004979 , E.mail : elba@icddrb.org
Estimated annual incidence of nephritic syndrome is 2-7 per $1,00,000$ children and the prevalence is $12-16$ per 100,000 . There is epidemiological evidence of higher incidence of nephritic syndrome in children from South Asia and Africa ${ }^{2}$ 3 .

Idiopathic nephritic syndrome id commonly seen $95 \%$ of patients ${ }^{6}, 80 \%$ of whom show histological features of minimal change nephritic syndrome (MCNS) and have good prognosis 7,8 . Although recurrence is common in nephritic syndrome, $90-95 \%$ of children with MCNS are responsive to steroid therapy with complete clinical, biochemical remission and have excellent long term prognosis ${ }^{2,67,9}$, Steroid sensitive nephritic syndrome (SSNS) comprises 80 $90 \%$ of syndrome and rest $10-20 \%$ nephritic syndrome are steroid resistant (SRNS) ${ }^{\text {sin }}$.

The objectives of the study were to compare the difference in weight loss between admission weight and dry weight, difference in weight in weight gain after steroid therapy and pattern of oedema among different groups of childhood jdiopathic nephritic syndrome.

\section{Methods}

This observational prospective study was carried out in the pediatric Nephrology unit of the department of pediatrics of 
Bangabandhu Sheikh Mujib Medical University (BSMMU) from January 2003 to January 2005. A total of 480 children with primary nephritic syndrome were admitted in BSMMU during the study period. Forty three (43) children were randomly selected who were aged 1-15 yrs. Among them, 19 had steroid resistant nephritic syndrome (SRNS) leveled as group B and 24 were steroid sensitive nephritic syndrome (SSNS) leveled as group C, in SSNS group 11 children had frequent relapse, steroid dependent nephritic syndrome (FRNS + SDNS) group $\mathrm{C} 1$ and 13 had infrequent relapse, first attack nephritic syndrome (IFRNS + FANS), group C2. Among the 19 children with SRNS, the histopathological reports on biopsy were mesangial proliferative glomerulosclerosis ( 9 children), MCNS (3 children), focal segmental glomerulosclerosis (3 children), membranoproliferative glomerulonephritis ( 2 children) and membranous glomerulonephritis ( 2 children).

Children below one year and above 15 years and those with congenital nephritic syndrome, nephritic syndrome secondary to systemic disease like systemic lupus erythematosis, hepatitis B, Henoch Schonlein purpura, falciparum malaria, lymphoma of amylodosis were excluded from the study. Those with severe protein energy malnutrition or Down's syndrome were also excluded.

Parents and guardians of the enrolled children were informed about the purpose and procedure of the study and written consent was obtained during enrollment. They were given the choice to withdraw from the study at any time during the course of the study. Data were collected by pre tested semi structured questionnaire. The study was approved by the Ethical Review committee of BSMMU.

\section{Investigations}

Urinary total protein (UTP) was measured by auto analyzer (RA 50 chemistry analyzer). Five (5) $\mathrm{ml}$ of venous blood sample was collected for estimation of serum complement C3 along with serum albumin, total protein, cholesterol, creatinine, blood urea and blood count including hemoglobin and ESR. Daily morning weight was taken with minimum clothing in digital bathroom scale and plotted in weight chart. Before taking weight digital bathroom scale was calibrated to zero. Weight was taken on admission. Weight taken after diuretics \& dietary manipulation and in some cases of refractory edema after albumin therapy designated as dry weight and finally after steroid therapy. Genital oedema was diagnosed by history \& clinical examination. Pleural effusion was diagnosed by history, clinical examination and Chest X-ray. Suspected pericardial effusion was confirmed by echo cardiograph.

Mantoux test (MT) and Bacillus Calmette - Guerine (BCG) acceleration tests were performed when indicated. Antinuclear antibody (ANA) and anti NDA double stranded antibody (anti ds DNA) were measurd by evzyme - linked immunosorbent assay (ELISA) in the children when indicated to rule out systemic disease. HbsAg was tasted by screening and ELISA. Chest X-ray and Ultrasonography of the kidneys, ureters and bladder were performed for all the patients. Renal biopsy was done for SRNS patients.

Table-I: comparison of weight on admission, dry weight, after administration of prednisolone and percent of weight \begin{tabular}{|l|l|l|l|}
$\begin{array}{l}\text { Change in different groups. } \\
\text { Parameters }\end{array}$ & Group B (N=19) & Group C1(N=11) & Group C2(N=13) \\
\hline
\end{tabular} Weight on admission (kg)

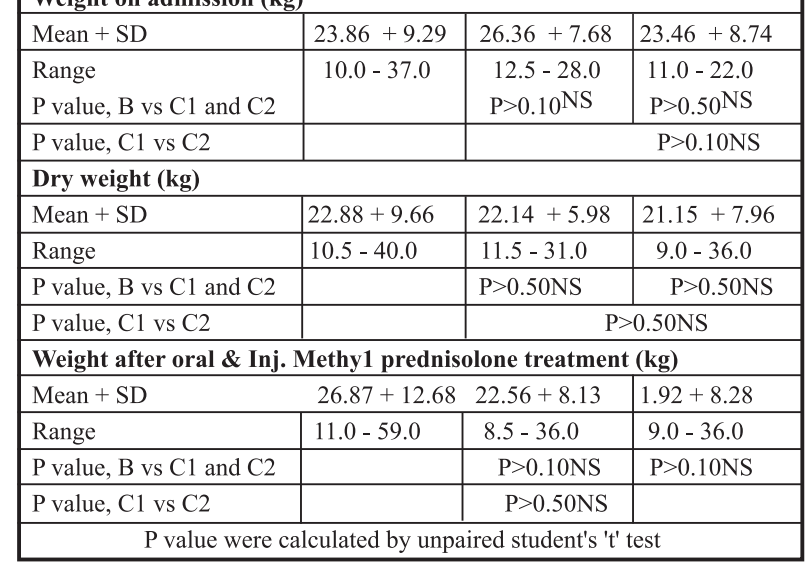

\section{Study definition}

SSNS was defined as responding to steroid therapy within 4 weeks after initiation of the therapy ${ }^{2,3}$, IFRNS was defined as less than 4 relapses within one year or less than 2 relapses within 6 months after initial responsive episode. Remission was defined as protein free urine for 3 consecutive days and relapse was defined as proteinuria (urine albumin $3+$ or more) for 3 consecutive days after responsive episode $e^{2,3}$. The occurrence of 2 consecutive relapses during alternate day prednisolone therapy or within 2 weeks of its discontinuation was defined as SDNS $^{2,3}$. No remission after 4 weeks of standard prednisolone therapy at $60 \mathrm{mg} / \mathrm{m}^{2} /$ day was defined

Table-II: Percent change of weight for steroid resistant an he two steroid sensitive groups.

\begin{tabular}{|c|c|c|c|c|c|}
\hline Parameters & \multicolumn{2}{|c|}{ Group B $(\mathrm{N}=19)$} & \multicolumn{2}{|c|}{ Group $\mathrm{C} 1(\mathrm{~N}=11)$} & roup $\mathrm{C} 2(\mathrm{~N}=13)$ \\
\hline \multicolumn{6}{|c|}{ Weight on admission $(\mathrm{kg})$} \\
\hline Mean + SD & \multicolumn{2}{|c|}{$23.83+9.29$} & \multicolumn{2}{|c|}{$26.36+7.68$} & $23.46+8.74$ \\
\hline \multicolumn{6}{|l|}{ Dry weight $(\mathrm{kg})$} \\
\hline \multicolumn{2}{|l|}{ Mean + SD } & \multicolumn{2}{|c|}{$22.88+9.66$} & $22.14+5.98$ & $21.15+7.96$ \\
\hline \multicolumn{2}{|c|}{$\begin{array}{l}\text { Percent change of dry wt. } \\
\text { from admission weight } \\
\text { Dry weight }(\mathrm{kg})\end{array}$} & \multicolumn{2}{|c|}{-4.36} & -15.30 & -10.10 \\
\hline \multicolumn{2}{|l|}{ Mean + SD } & \multicolumn{2}{|c|}{$22.88+9.66 \mid 2$} & $22.14+5.98$ & $21.15+7.96$ \\
\hline \multicolumn{6}{|c|}{ Weight after oral \& Inj. Methy1 prednisolone treatment $(\mathrm{kg})$} \\
\hline \multicolumn{2}{|l|}{ Mean + SD } & \multicolumn{2}{|c|}{$26.87+12.68$} & $22.56+8.13$ & $21.92+8.28$ \\
\hline \multicolumn{2}{|c|}{$\begin{array}{l}\text { Percent change of wt. } \\
\text { after oral \& Inj. } \\
\text { Methylprednisolone } \\
\text { treatment from dry wt. }\end{array}$} & \multicolumn{2}{|c|}{+16.01} & +0.26 & +3.49 \\
\hline
\end{tabular}


as SRNS ${ }^{2,3}$. They were treated with 6 pulses of alternate day intravenous methyl prendnisolone $(30 \mathrm{mg} / \mathrm{kg} /$ does $)$

\section{Statistical analysis}

Station andysis py ung SPSS. Unpaiked

Stgideht's test was used to compare between the groups.

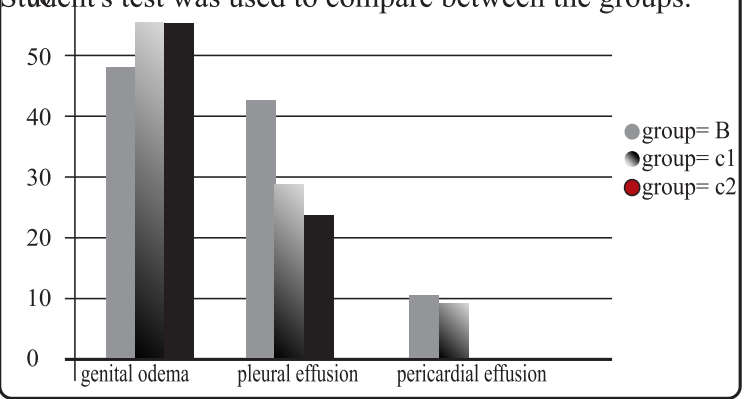

Fig-1: Oedema pattern in the steroid resistant \& two steroid sensitive Nephritic syndrome. Group B $(\mathrm{N}=19)$, Group c1 $(\mathrm{N}=11)$, Group c2 $(\mathrm{N}=13)$

\section{Results}

Table 1 and 2 Shows that mean ( + SD) weight of the children of SRNS, frequent relapse steroid dependent and Infrequent relapse first attack were $23.83+9.29,26.36+$ 7.68 and $23.46+8.74 \mathrm{~kg}$, respectively. The dry weight in these three groups was $22.88+9.66,22.14+5.98$ and 21.15 $+7.96 \mathrm{~kg}$, respectively. After steroid therapy (oral prednisolone and intravenous methyl prednisolone), weight in these there groups were $26.87+12.68,22.56+8.13$ and $21.92+8.28 \mathrm{~kg}$, respectively. The difference between admission weight and dry weight were $4.36,15.3$ and 10.0 percent respectively in the above three groups. After steroid therapy, these groups gained $16.01,0.26$ and 3.49 percent weight respectively.

Figure 1. shows that genital oedema were present in 47.5, 54.5 and 30.8 percent of patients in SRNS, frequent relapse steroid dependent and infrequent relapse first attack group, respectively. Pleural effusion were seen in 42.1, 27.3 and 23.1 percent of patients in SRNS, frequent relapse steroid dependent and Infrequent relapse first attack group, respectively. Pericardial effusion was seen in

10.5 and 9.1 percents in SRNS, steroid dependent frequent relapse first attack group, respectively. None in the infrequent relapse nephritic syndrome first attack group had pericardial effusion.

\section{Discussion}

Ninety five percent of nephritic syndromes are idiopathic (INS) and $80 \%$ of idiopathic childhood nephritic syndromes are MCNS. Presence of hypertension, gross hematuria and impaired renal function indicate significant glomerular lesion and severe edema and genital edema also indicate severe disease $^{9,11}$.

Here different study groups gained 10.1 percent (IFNS+FANS group), 15.3 percent (FRNS+SDNS group), and 4.36 percent (SRNS group) weight by oedema fluid. Some of the SRNS could not be dried because of refractory nature of this disease.

Again after steroid therapy they gained 3.49, 0.26 and 16.01 percent weight, infrequent relapse first attack and frequent relapse steroid dependent and SRNS group respectively, by fluid retention. Prasad noted 10 percent weight gain by oedema fluid when patients were dry after treatment ${ }^{12}$. Oedema becomes clinically detectable when fluid retention exceeds 3-5 percent of body weight ${ }^{10}$.

\section{Conclusion}

Steroid resistant nephritic syndrome cases lose less weight only 4.36 percent whereas frequently relapse steroid dependent and infrequent relapse first attack nephrotic syndrome lose more weight 15.3 and 10.0 percent respectively.

Genital oedema was more marked in frequent relapse steroid- dependent group 54.5 percent of patients. But in steroid- dependent group 47.5 percent and in 30.8 percent of patients of infrequent relapse first attack nephritic syndrome group has genital oedema.

Pleural effusion was more marked in steroid resistant group 42.1 percent of patients. But in frequent relapse steroiddependent group 27.3 percent and in 23.1 percent of patients of infrequent relapse first attack nephritic syndrome group.

None in the infrequent relapse first attack nephritic syndrome group had pericardial effusion. But in 10.5, and 9.1 percent of patients in SRNS, steroid dependent frequent relapse first attack group has pericardial effusion.

Group B $=$ Steroid resistant (SRNS)

Group C1 (Steroid sensitive) $=$ FRNS $=$ SDNS (Frequent relapsing + Steroid dependent)

Group C2 (Steroid sensitive) = IFRNS (Infrequent relapsing nephritic syndrome).

\section{Reference}

1. ISKDC (International study of Kidney disease in children). Nephrotic Syndrome in children: Prediction of histopathology from clinical and laboratory characteristics at time of diagnosis. Kidney Int 1978; 13: 159165.

2. Srivastva RN, Bagga A. Nephrotic Syndrome. In Srivasrava RN, Bagga A, edn. Pediatric Nephrology, 4th edn, New Delhi: Jaypee Brothers, Medical Publishers (P) Ltd, 2005:161-167.

3. Abdur Rahman MB, Aikhonbare HA, Babaoye FA, Sathiakumae N, Narayana PT. Clinicopathological features of childhood Nephrotic Syndrome in Northen Nigeria. QJ Med 1990; 75:563-576.

4. Eddy AA, Symons JM, Nephrotic Syndrome in childhood. Lancet 2003;362:629-639.

5. Mc Kinney PA, Feltbower RG, Brocklebank JT, Fizpatrick MM. Time trends and ethnic patterns of childhood Nephrotic Syndrome in Yooukshire. UK. Pediatric Nephrology 2001; 16: 1040-1044

6. Churg S, Habib R, White RH, Pathology of Nephrotic Syndrome in children. A report for the International study of Kidney disease in children. Lancet 1970; 1: 1299-1302.

7. Salcedo JR, Thabet MA, Latta K, Chan JC. Nephrosis in childhood. 
Nephron 1995; 71:375-385

8. Bebrman RE, Kliegman RM, Jenson HBB. Nephrotic Syndrome : Nelsom

Text book of Pediatrics, 17th ed. Philadelphia: WB Sanuders Company.

2004: 1753-1757

9. ISKDC (International study of Kidncy disease in children). The Primary

Nephrotic Syndrome in children. Identification of patients with minimal

change Nephrotic Syndrome from initial response to prednisolone. A report of the Intemational study of Kidney disease in children. J Pediatric 1981;

98:561-564

I0. Niaudet P. Steroid sensitive idiopathic Nephrotic Syndrome in children.

In : avner ED, barmol WE, Niaudet $P$, eds. Pediatric Nptrology, 5th ed

Pbiladelphia: Lippincon Willians and Wilkins, 2004:543-553
II. White RHR, Glasgos EF, Mills RI, Climico pathological study of Nephrotic Syndrome in childhood. Lancet 1970; 1,27:1353-1359.

12. Prasad $\mathrm{S}$. Immunoglobulin $\mathrm{G}$ (Ig $\mathrm{G}$ ) level in frequently relapsing nephritic Syndrome and its predictive value Thesis BSMMU and Dhaka Shishu (Children) Hospital .2004 